\title{
Reliability and psychometric properties of the Greek translation of the state-trait anxiety inventory form Y: preliminary data
} KN Fountoulakis*, M Papadopoulou, S Kleanthous, A Papadopoulou, V Bizeli, G Agori, I Nimatoudis, A Iacovides and GS Kaprinis

Address: 3rd Department of Psychiatry, Aristotle University of Thessaloniki, Greece

* Corresponding author

from International Society on Brain and Behaviour: Ist International Congress on Brain and Behaviour Hyatt Regency Hotel, Thessaloniki, Greece, 20-23 November, 2003

Published: 23 December 2003

Received: I November 2003

Annals of General Hospital Psychiatry 2003, 2(Suppl I):S80

This article is available from: http://www.general-hospital-psychiatry.com/content/2/SI/S80

\section{Background}

The State-Trait Anxiety Inventory form $\mathrm{Y}$ is a brief self-rating scale for the assessment of state and trait anxiety. The aim of the current preliminary study was to assess the psychometric properties of its Greek translation.

\section{Material and Methods}

121 controls $27.22 \pm 10.61$ years old, and 22 anxietydepressed patients $29.48 \pm 9.28$ years old entered the study. In 20 of them the instrument was re-applied 1-2 days later. Translation and Back Translation was made. The clinical diagnosis was reached with the SCAN v 2.0 and the IPDE. The Symptoms Rating Scale for Depression and Anxiety (SRSDA) and the EPQ were applied for crossvalidation purposes. The Statistical Analysis included the Pearson Correlation Coefficient and the calculation of Cronbach's alpha $(\alpha)$

\section{Results}

The State score for controls was $24.95 \pm 11.36$ and the Trait score was $27.88 \pm 11.43$. The respected scores for depressed subjects were $44.91 \pm 9.18$ and $43.50 \pm 9.99$. Both State and Trait scores followed the normal distribution in control subjects. Cronbach's alpha was 0.19 for the State and 0.39 for the Trait subscale. The Pearson Correlation Coefficient between State and Trait subscales was 0.79 . Both subscales correlated fairly with the anxiety subscale of the SRSDA. Test-retest reliability was excellent, with Pearson coefficient being between 0.77 and 0.98 for individual items and equal to 0.96 for State and 0.98 for Trait.

\section{Discussion}

The current study provided preliminary evidence concerning the reliability and the validity of the Greek translation of the STAI-form Y. Its properties are generally similar to those reported in the international literature, but further research is necessary. 